$11-2007$

\title{
On Internal Cone Cracks Induced by Conical Indentation in Brittle Materials
}

J. Yan

University of Delaware

Anette M. Karlsson

Cleveland State University, a.karlsson@csuohio.edu

X. Chen

Columbia University

Follow this and additional works at: https://engagedscholarship.csuohio.edu/enme_facpub

Part of the Mechanical Engineering Commons

How does access to this work benefit you? Let us know!

\section{Publisher's Statement}

NOTICE: this is the author's version of a work that was accepted for publication in Engineering Fracture Mechanics. Changes resulting from the publishing process, such as peer review, editing, corrections, structural formatting, and other quality control mechanisms may not be reflected in this document. Changes may have been made to this work since it was submitted for publication. A definitive version was subsequently published in Engineering Fracture Mechanics, 74, 16, (11-01-2007); 10.1016/j.engfracmech.2006.12.005

\section{Original Citation}

Yan, J., Karlsson, A. M., and Chen, X., 2007, "On Internal Cone Cracks Induced by Conical Indentation in Brittle Materials," Engineering Fracture Mechanics, 74(16) pp. 2535-2546.

This Article is brought to you for free and open access by the Mechanical Engineering Department at EngagedScholarship@CSU. It has been accepted for inclusion in Mechanical Engineering Faculty Publications by an authorized administrator of EngagedScholarship@CSU. For more information, please contact library.es@csuohio.edu. 


\title{
On internal cone cracks induced by conical indentation in brittle materials
}

\author{
J. Yan ${ }^{\text {a }}$, A.M. Karlsson ${ }^{\mathrm{a}, *}, \mathrm{X}$. Chen $^{\mathrm{b}}$ \\ a Department of Mechanical Engineering, University of Delaware, Newark, DE 19716-3140, USA \\ ${ }^{\mathrm{b}}$ Department of Civil Engineering and Engineering Mechanics, Columbia University. New York, NY 10027-6699. USA
}

\section{Introduction}

Indentation techniques are commonly used to characterize the mechanical properties of materials. Comparing with traditional testing techniques, instrumented indentation is an effective and simple method which requires minimum sample preparation. Sharp indentation can be employed to reveal the elastic-plastic properties [1,2] and residual stresses [3-5] of a material, and may also be used to determine the fracture characteristics of brittle materials - the focus of this paper.

Several types of cracks may appear in brittle materials during indentation, depending on the indenter shape (conical, spherical, flat punch, Berkovich, Vickers, etc.) and on the properties of the material. The finite plastic deformation occurring beneath the indenter can induce large stresses during loading, causing radial (median) cracks during Berkovich/Vickers indentation [6,7]. The elastic recovery during unloading also leads to stress redistribution, which is responsible for lateral cracking [8-10]. For different material systems, variants of lateral and radial crack systems are observed [6,7]. Early studies in the 70's and 80's [11-18] used dimensional analysis and elastic-contact (or void-expansion) based models to estimate the energy release rate.

\footnotetext{
- Corresponding author. Tel.: +1 3028316437.

E-mail address: karlsson@udel.edu (A.M. Karlsson).
} 


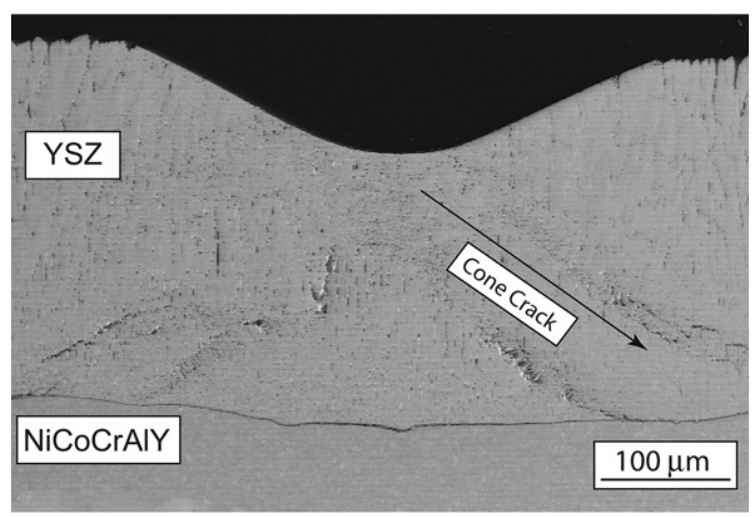

Fig. 1. An example of a cone crack originating in the vicinity of the indenter tip shown in a SEM image of a thermal barrier coating after Rockwell indentation. Two major layers of the coating are visible, the ceramic top coat consisting of Yttria Stabilized Zirconia (YSZ) and the metallic bond coat (NiCoCrAlY). (As coated, indentation force $200 \mathrm{~N}$.)

Various forms of cone cracks are observed in brittle materials when an axisymmetric indenter is used (e.g. conical, spherical, or cylindrical) - this is also referred to as "the Hertzian cone crack." Lawn and co-workers have investigated cone cracks developing from the free surface in spherical indentation $[7,12,13,19]$, and the inner cone cracks developing in brittle solids submerged in water [20]. Besides bulk materials, cone cracks developed beneath a spherical indenter in multi-layered structures are characterized by Evans and co-workers $[21,22]$. A method to determine the fracture toughness of a material based the length of the induced cone cracks from a spherical indentation tests was suggested in $[23,24]$. In addition, the formation of Hertzian cone cracks was simulated in $[25,26]$. Most work pertaining to cracks induced by Vickers indentation investigates surface cracks (e.g., [27,28]), however, the developments of cracks under a Vickers indentation is explored experimentally for glass in [29,30], where cone cracks are seen to develop at the tip of the indenter in Ref. [29].

Compared to the relatively well-understood response due to spherical and cylindrical indentation, cone cracks developed during conical indentation are not completely understood. Preliminary experimental results [31] and from our own recent work, Fig. 1, have indicated that cone-cracks indeed can develop during conical indentation. This class of cracks has not (to the knowledge of the authors) been systematically investigated. Thus, the theoretical aspect of the formation of internal cone cracks induced by conical indentation is therefore the focus of this paper. In this initial study, we will characterize the requirements for internal cone cracks to develop in a homogeneous material. We will show that cone cracks indeed can develop in brittle materials.

\section{Problem formulation}

The axisymmetric problem of indentation induced internal cone crack is sketched in Fig. 2. The half apex angle of the rigid conical indenter is $\alpha=70.3^{\circ}$. The maximum indentation depth is $\delta$. The cone crack developing at max indentation load is assumed to be of length $a$, and the half-apex angle of the cone crack is $\pi / 2-\theta$. The material under consideration is assumed semi-infinite and linear-elastic, perfectly-plastic, which is a good approximation for brittle materials where indentation cracking are observed - for these materials, their yield stress is usually high and thus the strain hardening is negligible [8-10].

\subsection{Superposition principle}

The commonly used superposition technique will be employed to determine the stress intensity of the system. The superposition techniques can be used when the crack tip plasticity can be ignored, that is, for brittle material. For clarity of the presentation, we will review the general concept of this technique (even though it can be found in most text books treating fracture mechanics).

Consider an elastic, crack free body, Fig. 3a, subjected to the prescribed tractions $T_{u}$ over the boundary $S_{T}$ and the prescribed displacements $u_{i}$ over the boundary $S_{u}$. The internal stress $\sigma_{\mathrm{i}}$ is generated from the bound- 


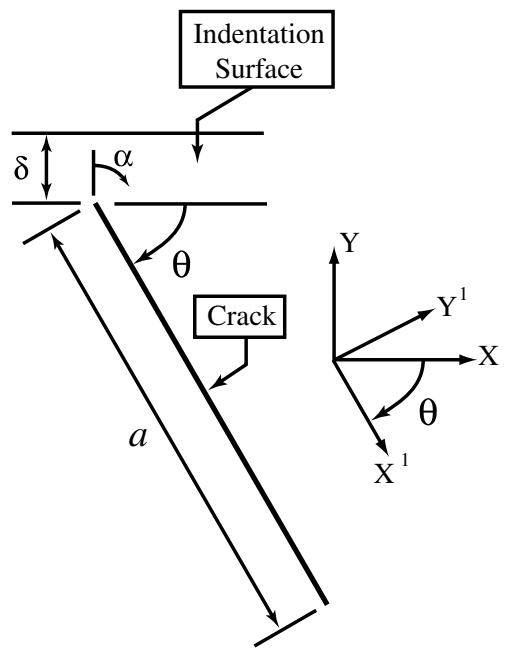

Fig. 2. Schematic of an indented surface and the associate crack in a brittle material.

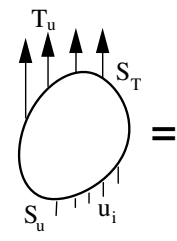

a

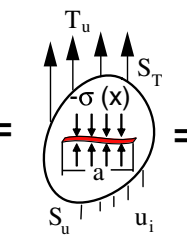

b

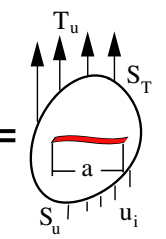

C

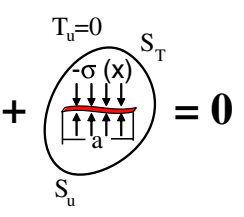

d

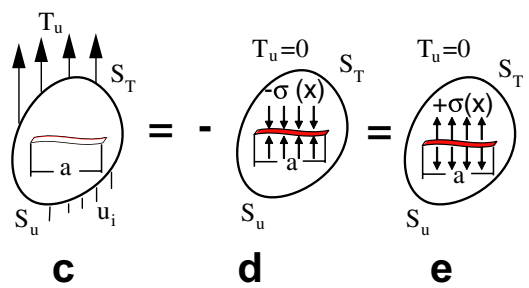

Fig. 3. Superposition technique - the general approach.

ary conditions. This case will be referred to as case A. Consider next an equivalent elastic body (with the same boundary conditions) containing a crack, Fig. 3b, referred to as case B. A stress field, $-\sigma(x)$, can be applied over the crack faces, closing the crack and effectively eliminate the presence of the crack. Thus, case B is identical to case A. Case B is a superposition of two cases: C and D, illustrated in Fig. 3c and d, respectively. Case $\mathrm{C}$ has an unloaded crack and the boundary conditions as described in $\mathrm{B}$; whereas case $\mathrm{D}$ is only subjected to a surface traction on the crack. Within the framework of linear fracture mechanics, the stress intensity factor $K$ is additive and it must hold that

$$
K_{\mathrm{C}}+K_{\mathrm{D}}=K_{\mathrm{B}}=K_{\mathrm{A}}=0
$$

thus

$$
K_{\mathrm{C}}=-K_{\mathrm{D}}
$$

where the index denotes the cases $\mathrm{A}-\mathrm{D}$, respectively. We next note that the stress $-\sigma(x)$ required to close the crack in $\mathrm{B}$, is equivalent to the negative stress that the original structure A carried in the corresponding area of 


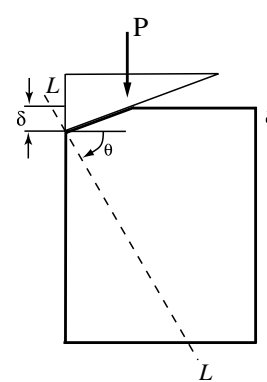

A

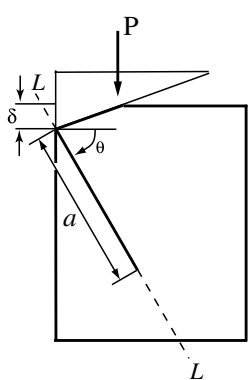

$\mathrm{C}$

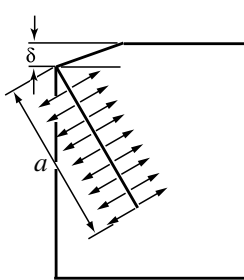

$\mathrm{E}$

Fig. 4. Superposition technique as applied to the current problem.

the crack in B. Finally, we introduce case E (Fig. 3e), where the crack opening stress $\sigma(x)$ is imposed on the crack. It follows that

$$
K_{\mathrm{C}}=K_{\mathrm{E}}
$$

The method of superposition is commonly used for solving case $\mathrm{C}$ by first calculating the internal stress for A (no crack) followed by determining $K_{\mathrm{E}}$ (crack with tractions only).

We will use the superposition technique described above for the current problem of interest (Fig. 2). To this end, we will first solve the problem without a crack, as shown in Fig. 4a. The problem we are considering, i.e. indentation induced cone cracking, corresponds to the case in Fig. 4c where the crack develops as the maximum indentation load is applied. ${ }^{1}$ For a length corresponding to the assumed crack length $a$, stresses along the line $L-L$ in Fig. 4a are extracted and applied on a system corresponding to case E described above, as illustrated by Fig. 4e. Using Eq. (3) above, we can then determine the stress intensity of the crack as described in Fig. 2 (or Fig. 4c).

\subsection{Finite element model}

The numerical simulations are conducted with the commercially available finite element program ABAQUS, using PC workstations. The "rigid surface" option is used to simulate the (relatively) rigid indenter in a contact analysis. Two axisymmetric meshes are used to simulate cases A and E in Figs. 3 and 4. A typical mesh comprises more that 5000 eight-node axisymmetric elements with reduced integration. For the indentation problem, a fine grid is used adjacent to the indenter, to capture the large stress and strain gradients. In the subsequent cracking problem, the mesh is also refined near the vicinity of crack tip to reproduce the $1 / \sqrt{r}$ singularity. Furthermore, "non-linear geometry" is used to allow for finite strains and deformations when \$imulating case A in Fig. 4 (corresponding to indentation loading until crack initiation), whereas small strains are assumed when simulating case E in Fig. 4 where the conditions for the crack is investigated.

The stress field is acquired from the elastic-plastic indentation model at maximum penetration (model A in Fig. 4), and superimposed on the elastic crack model (model E in Fig. 4). In model A, the material is assumed to be linear-elastic, perfectly-plastic, with the von Mises criteria governing the yielding. The elastic modulus is denoted by $E$ and the yield strength is $\sigma_{\mathrm{y}}$. During indentation, friction according to Coulomb's law is used with the coefficient of friction set to be 0.1 (which is essentially frictionless). From this model, the normal and shear stresses that act over the putative crack are extracted using interpolation of the stress field, which are then imposed on the nodes and elements along the crack surface in model E. The $J$-integral around the crack tip is computed, from which the fracture toughness is obtained from model E. The path-independency of the $J$-integral has been verified and the results are taken from the averaged values of several contours around of the crack tip. Moreover, from the ratio between shear and normal stresses ahead of the crack tip, the mode mixity can be determined, discussed below.

\footnotetext{
${ }^{1} \mathrm{We}$ assume that the indentation is interrupted once the crack appears. The incipience of the crack in a physical test can be determined by observing the force-displacement response, or from acoustic emission. Thus, we will in this study not consider the state and evolution of the crack if the indentation load is increased after its formation.
} 


\subsection{Strategies for evaluating the results}

For simplicity, we will assume that the crack will propagate with a constant angle relative the surface (Fig. 2), which is consistent with the cone cracks observed in preliminary experimental results [31]. With the assumption that the material is brittle, linear-elastic material properties in the vicinity of the crack tip can be assumed. Thus, the energy release rate, $G$, and the $J$-integral are identical quantities. The stress intensity factor can be determined by

$$
K=\sqrt{G \frac{E}{1-v^{2}}}(
$$

for plane strain conditions, where $v$ is Poisson's ratio and fixed at 0.3 in this study. The stress intensity factor obtained in Eq. (4) is the total stress intensity. However, we are more interested in the mode I stress intensity factor, since a crack usually propagates in mode I in a homogeneous brittle material [32]. Thus, the mode mixity must be determined, which is quantitatively represented by the mode mixity angle, $\psi$,

$$
\tan \psi=\frac{\sigma_{x^{\prime} y^{\prime \leftarrow}}}{\sigma_{y^{\prime} y^{\prime \leftarrow}}}
$$

where $\sigma_{x^{\prime} y^{\prime}}, \sigma_{y^{\prime} y^{\prime}}$ are the shear and the crack opening stress, respectively, measured just ahead of the crack tip in the local coordinate system described in Fig. 2. The mode I stress intensity factor is determined by

$$
K_{\mathrm{I}}=K \cos \psi
$$

We recall that $\psi=0^{\circ}$ correspond to pure mode I (tensile) and $\psi=90^{\circ}$ corresponds to pure mode II (shear).

To cover a range of properties it is convenient to express the results in dimensionless form. Since the only length scale involved in the problem is the indentation depth, the non-dimensional crack length is $a / \delta$. The angle characterizing the crack path is $\theta$, as shown in Fig. 2. The non-dimensional material property is $E / \sigma_{\mathrm{y}}$. For most glasses and ceramic materials it holds that $10<E / \sigma_{\mathrm{y}}<200$. Furthermore, dimensional analysis (verified with numerical simulations not presented for brevity), show that the relationships for energy release rate and fracture toughness can be expressed as

$$
\begin{aligned}
& \frac{G}{a E /\left(1-v^{2}\right) \longleftarrow}=\nLeftarrow\left(\frac{a}{\delta}, \theta, \frac{E}{\sigma_{\mathrm{y}}}\right) \\
& \frac{K_{\mathrm{I}}}{\sqrt{a} \not /\left(1-v^{2}\right)}=\mathrm{t}\left(\frac{a}{\delta}, \theta, \frac{E}{\sigma_{\mathrm{y}}}\right)
\end{aligned}
$$

By varying $a / \delta, \theta$, and $E / \sigma_{\mathrm{y}}$ over a wide range, the functional forms of $g$ and $h$ can be determined from finite element simulations. For a given material, the optimum crack path $(\theta)$ (i.e., the mostly likely angle for crack propagation) is determined by the mode I stress intensity whereas the length of cone crack (once the initiated crack is arrested) depends on the fracture toughness of the material.

In what follows, we will first determine the likely angle of crack propagation, based on extensive finite element simulations over a range of properties. To this end, a maximum $K_{\mathrm{I}}$ criterion, as described below, will be used. With this established, we will present a method for determining the fracture toughness of a material when cone-cracks are observed due to a conical indentation.

\section{FE results}

We assume that the cone cracks are initiated beneath the indenter tip, as sketched in Fig. 2. Furthermore, we assume that the cone cracks develop at the maximum load, i.e., during the holding of maximum penetration depth of the conical indenter [6]. Lateral cracks may develop during unloading [8-10], but will not be considered here. In all simulations $\delta=0.4 \mathrm{~mm}$ and $E=100 \mathrm{MPa}$ and we vary $\sigma_{\mathrm{y}}$ to achieve a range of $E / \sigma_{\mathrm{y}}$, that is, a range of material properties. Once initiated, the crack is assumed to propagate quasi-statically along a straight path, until its energy release rate falls below the fracture toughness and arrest.

First, we will determine the preferred direction of crack propagation. By introducing a local coordinate system $\left(X^{1}-Y^{1}\right)$ rotated by an angle $\theta$ relative the material surface as indicated in Fig. 2, the stress-field associated 
with cracks adjacent to the indentation tip are revealed, for a set of assumed directions of crack-propagation. In Fig. $5 \mathrm{a}-\mathrm{c}$, the stress fields for $E / \sigma_{\mathrm{y}}=100$ at the maximum indentation depth are examined from different local coordinate systems $\left(X^{1}-Y^{1}\right)$ that have been rotated by $45^{\circ}, 60^{\circ}$, and $70^{\circ}$, respectively. Thus, the contour plots in Fig. 5 correspond to case "A" (Fig. 3) in our superposition scheme, where the $X^{1}$ axis in each selected coordinate system corresponds to a hypothetical direction of crack propagation. Both the "crack-opening stress," $\sigma_{y^{\prime} y^{\prime}}$, and the shear stress, $\sigma_{x^{\prime} y^{\prime}}$, are presented for each local coordinate system. As noted previously, in a homogeneous brittle material the crack will likely propagate in mode I corresponding to the case where the shear stress is vanishingly small in the local coordinate system. Thus, it follows that the crack propagates along a path where $K_{\mathrm{I}}$ has the maximum value and where $\sigma_{x^{\prime} y^{\prime \prime}}$ is zero. Since the crack path is assumed to be straight and only a finite number of possible crack propagation angles are investigated in this study, $K_{\mathrm{II}}$ may not be exactly zero; however the preferred direction where $\sigma_{x^{\prime} y^{\prime}}$ is approaching zero will be identified from the numerical analysis.

We now can determine the preferred direction of crack propagation by exploring in which direction $K_{\mathrm{I}}$ approaches its maximum. In order to do so, we first determine the $J$-integral from finite element analyses of the crack model in Fig. 4e. The normalized energy release rate for various assumed material combinations and normalized crack lengths, assuming material properties $E / \sigma_{\mathrm{y}}=20,100$, and 200 with local coordinate systems rotated by $45^{\circ}, 60^{\circ}, 65^{\circ}$, and $70^{\circ}$, are shown in Fig. 6. For $E / \sigma_{\mathrm{y}}=20$ (Fig. 6a), a putative crack aligned at
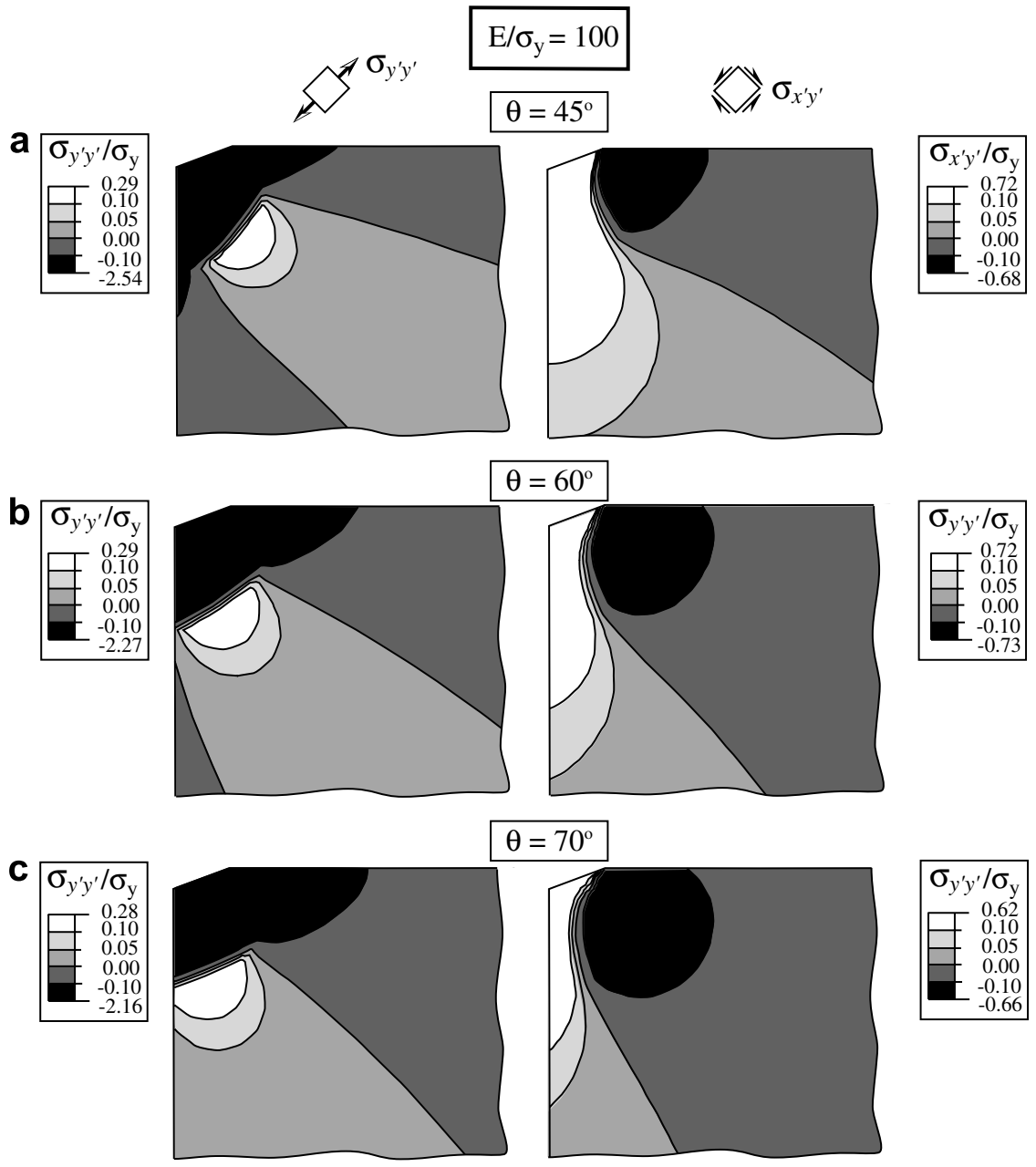

Fig. 5. Values of $\sigma_{\mathrm{yy}}$ and $\sigma_{\mathrm{xy}}$ shown in various local coordinate systems, corresponding to a set of hypothetical direction of crack propagation. (a) $\theta=45^{\circ}$, (b) $\theta=60^{\circ}$, and (c) $\theta=70^{\circ}$, where $\theta$ is defined in Fig. 3. The stresses are normalized with $\sigma_{\mathrm{y}}$. $E / \sigma_{\mathrm{y}}=100$. 


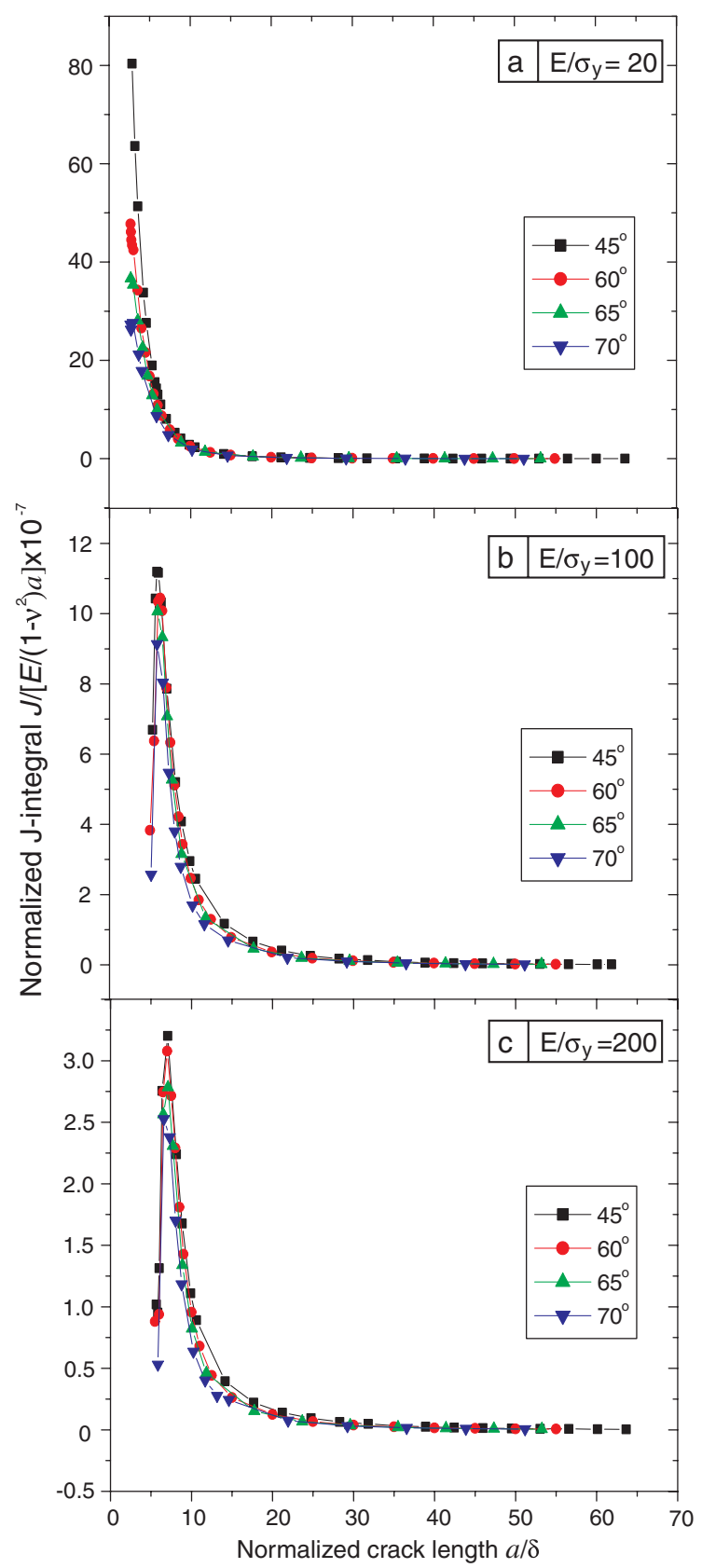

Fig. 6. Normalized $J$-integral as a function of the normalized crack length $a / \delta$ for (a) $E / \sigma_{\mathrm{y}}=20$; (b) $E / \sigma_{\mathrm{y}}=100$; (c) $E / \sigma_{\mathrm{y}}=200$. Note the different scale for each $E / \sigma_{\mathrm{y}}$.

$45^{\circ}$ angle gives the maximum normalized energy release rate. As the crack propagates, the energy release rate peaks at about $a / \delta=5$ and then dramatically decreases with further increasing of the normalized putative crack length. The same tendency is observed for cases where $E / \sigma_{\mathrm{y}}=100$ (Fig. 6b) and $E / \sigma_{\mathrm{y}}=200$ (Fig. 6c). The maximum value of the normalized energy release rate for $E / \sigma_{\mathrm{y}}=20$ (Fig. 6a) is more than 20 times larger than for $E / \sigma_{\mathrm{y}}=200$ (Fig. 6c).

However, the maximum value of the $J$-integral is not necessarily related to the maximum value of $K_{\mathrm{I}}$, since the mode mixity might not vanish for the selected angles. Using Eqs. (4)-(6) the mode mixity and finally $K_{\mathrm{I}}$ can be determined. For all cases of $E / \sigma_{\mathrm{y}}$, the mode mixity for $65^{\circ} \mathrm{crack}$ angle are the closest to 0 , which correspond 


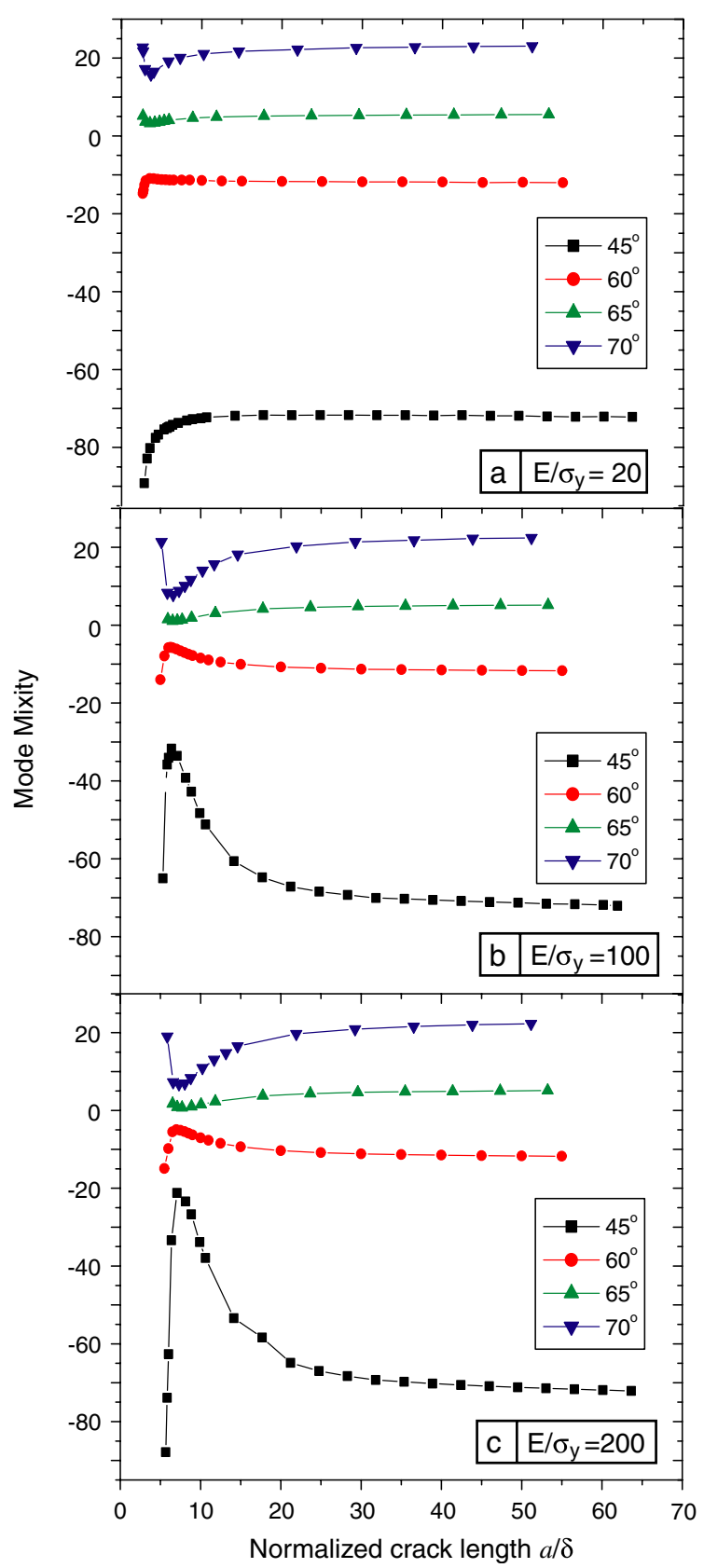

Fig. 7. Mode mixity as a function of the normalized crack length for (a) $E / \sigma_{\mathrm{y}}=20$; (b) $E / \sigma_{\mathrm{y}}=100$; (c) $E / \sigma_{\mathrm{y}}=200$.

to primarily mode I (Fig. 7). The corresponding normalized $K_{\mathrm{I}}$ values, according to Eq. (6), are shown in Fig. 8, for $E / \sigma_{\mathrm{y}}=20,100$, and 200 and crack paths aligned at $45^{\circ}, 60^{\circ}, 65^{\circ}$, and $70^{\circ}$, respectively. In Fig. 9, it is shown that when the crack angle is $60^{\circ}$, the highest normalized $K_{\mathrm{I}}$ values are reached for all cases considered. Thus, when considering the mode mixity, the crack growth may be deduced to occur in a $65^{\circ}$ angle, whereas considering the maximum $K_{\mathrm{I}}$ suggests an optimum crack propagation direction at $60^{\circ}$. This small inconsistency - maximum $K_{\mathrm{I}}$ does not correspond to vanishing shear force - may indicate that the preferred direction of propagation lies in between the two angles. Based on the maximum $K_{\mathrm{I}}$ criterion, the cracks are assumed to propagate (approximately) in the $60^{\circ}$ direction in the following reverse analysis. 


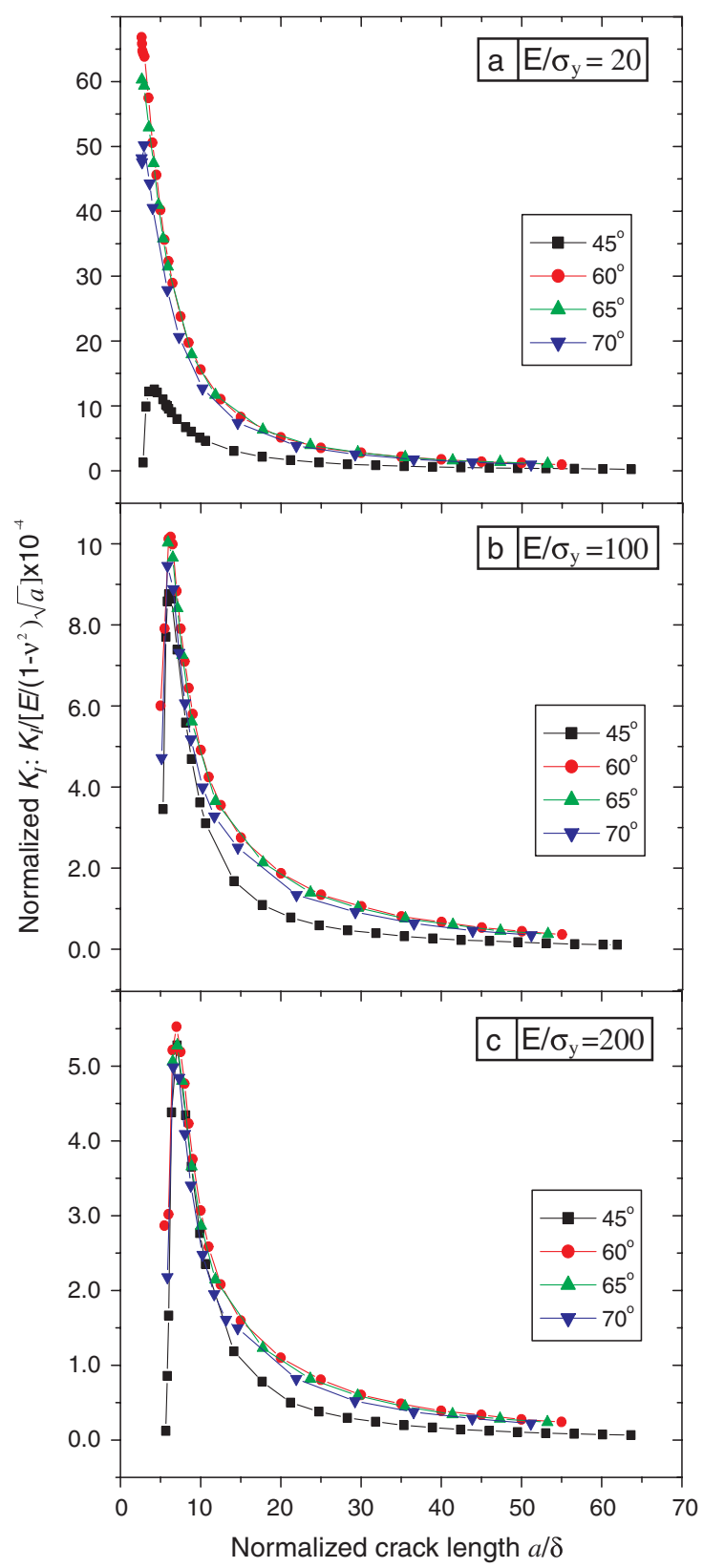

Fig. 8. Normalized $K_{\mathrm{I}}$ as a function of the normalized crack length for (a) $E / \sigma_{\mathrm{y}}=20$; (b) $E / \sigma_{\mathrm{y}}=100 ;$ (c) $E / \sigma_{\mathrm{y}}=200$.

We note that a "local maximum" of the stress intensity factor is found around $30^{\circ}$ (Fig. 9), in particular for materials with low values of $E / \sigma_{\mathrm{y}}$. Thus, under particular conditions, a crack may propagate in a $30^{\circ}$ direction. This could for example be triggered by pre-existing flaws favoring the $30^{\circ}$ direction.

\section{Reverse analysis to determine the fracture toughness}

Assuming that an internal cone crack is induced due to a conical indentation experiment, we will now discuss a method to determine the fracture toughness of the tested material. Based on the results in the previous chapter, we will assume that the crack will propagate in a $60^{\circ}$ angle relative the material surface. Thus, Eq. (8) can be simplified to 


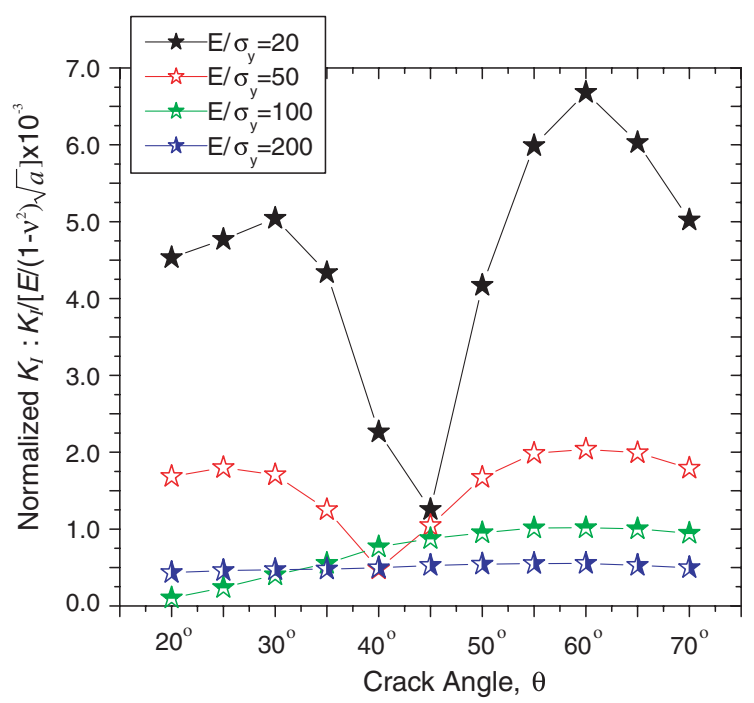

Fig. 9. For each material combination and assumed crack angle, the maximum normalized $K_{\mathrm{I}}$ as a function of assumed crack angle. A global maximum of $K_{\mathrm{I}}$ is found around $\theta=60^{\circ}$.

Table 1

Coefficients of Eq. (10) for four material combinations

\begin{tabular}{llllll}
\hline$E / \sigma_{\mathrm{y}}$ & $y_{0}$ & $A_{1}$ & $t_{1}$ & $A_{2}$ & $t_{2}$ \\
\hline 20 & 0 & 0.01149 & 3.93233 & $9.96482 \mathrm{E}-4$ \\
50 & 0 & 0.00559 & 3.59221 & $7.97102 \mathrm{E}-4$ & 23.37740 \\
100 & 0 & 0.00620 & 2.82314 & $5.28224 \mathrm{E}-4$ \\
200 & 0 & 0.00303 & 3.49492 & $2.13278 \mathrm{E}-4$ & 19.46045 \\
\hline
\end{tabular}

$$
\left.\frac{K_{\mathrm{I}}}{\sqrt{a} \not /\left(1-v^{2}\right)}\right|_{\theta=60^{\circ}}=h \frac{a}{\delta},\left.\frac{E}{\sigma_{\mathrm{y}}}\right|_{\theta=60^{\circ}}
$$

Using the decay part of the normalized $K_{\mathrm{I}}$ from the FE-simulations (Fig. 8), the results from the $60^{\circ}$ angle is fitted using a second order exponential decay functions, which leads to

$$
\frac{K_{\mathrm{I}}}{\sqrt{a} \not /\left(1-v^{2}\right)}=\dot{y}_{0}+A_{1} \times \mathrm{e}^{\left(-\frac{a / \delta}{t_{1}}\right)}\left(+A_{2} \times \mathrm{e}^{\left(-\frac{a / \delta}{t_{2}}\right)}(\right.
$$

The coefficients $\left(y_{0}, A_{1}, t_{1}, A_{2}, t_{2}\right)$ for various $E / \sigma_{\mathrm{y}}$ are listed in Table 1 and the fitting is shown in Fig. 10. For a given material and assuming that $E / \sigma_{\mathrm{y}}$ is known, the fracture toughness, $K_{\mathrm{I}}^{C}$, of that material can be calculated directly from Eq. (10), under the condition that the arrested crack length for a known indentation depth, $\delta$, can be measured. This is achieved by letting $K_{\mathrm{I}}=K_{\mathrm{I}}^{C}$ in Eq. (10). Alternatively, during reverse analysis, the crack length can be determined by providing the indentation depth, $\delta$, and the fracture toughness, $K_{\mathrm{I}}^{C}$.

As mentioned in the introduction, experimental results pertaining to internal cone cracks induced by conical indentation of bulk material are not available in the literature. At a later stage, we are planning to conduct these sets of experiments in our laboratory to verify our simulations, but results are not available yet. However, in order to illustrate and quantify the numerical scheme presented in this paper we determined the predicted crack length for a set of brittle materials.

Using published material data for Glassy Carbon [30], Zirconia ${ }^{2}$, fine grained $\mathrm{Al}_{2} \mathrm{O}_{3}$ [24] and Mullite ${ }^{2}$, Table 2 shows the predicted crack lengths for two assumed indentation depths. Even though we cannot

\footnotetext{
${ }^{2}$ Zirconia and Mullite data are estimated based a range of sources and in-kind experience.
} 


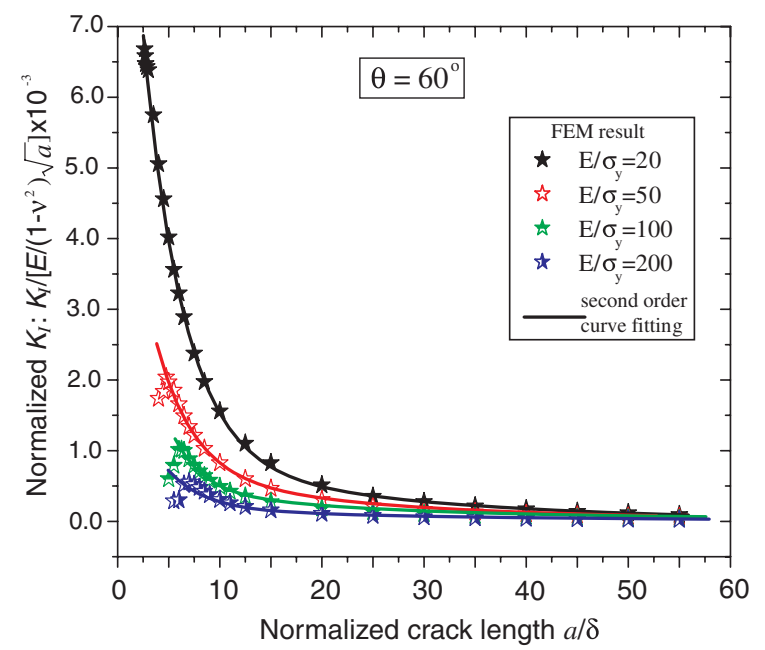

Fig. 10. Curve fitting for reverse analysis of for the case of $\theta=60^{\circ}$.

Table 2

Virtual experiments to determine crack lengths, assuming that the material properties are known

\begin{tabular}{|c|c|c|c|c|c|c|c|}
\hline \multicolumn{7}{|l|}{ Input } & \multirow{2}{*}{$\begin{array}{l}\text { Result } \\
a(\mathrm{~mm})\end{array}$} \\
\hline Material & $E(\mathrm{GPa})$ & $\sigma_{\mathrm{y}}(\mathrm{MPa})$ & $E / \sigma_{\mathrm{y}}$ & $v$ & $K_{\mathrm{I}}^{C}\left(\mathrm{MPa} \mathrm{m}^{1 / 2}\right)$ & $\delta(\mathrm{mm})$ & \\
\hline \multirow[t]{2}{*}{ Glassy carbon [30] } & 28 & 136 & 205 & 0.3 & 0.58 & 0.06 & 0.209 \\
\hline & & & & & & 0.40 & 4.174 \\
\hline \multirow[t]{2}{*}{ Zirconia $^{\mathrm{a}}$} & 200 & 1750 & 114 & 0.3 & 11.0 & 0.10 & 0.125 \\
\hline & & & & & & 0.40 & 2.635 \\
\hline \multirow[t]{2}{*}{ Fine grained $\mathrm{Al}_{2} \mathrm{O}_{3}$ [24] } & 370 & 3,000 & 123 & 0.22 & 3.77 & 0.06 & 0.737 \\
\hline & & & & & & 0.40 & 14.259 \\
\hline \multirow[t]{2}{*}{ Mullite $^{\mathrm{a}}$} & 150 & 550 & 272 & 0.25 & 2.0 & 0.06 & 0.404 \\
\hline & & & & & & 0.40 & 5.993 \\
\hline
\end{tabular}

${ }^{a}$ Zirconia and Mullite data estimated based a range of sources. Indentation depth of $0.10 \mathrm{~mm}$ was simulated for Zirconia instead of $0.06 \mathrm{~mm}$, since the smaller indentation depth did not predict crack growth.

directly compare these results to experimental data, the magnitude of the cracks are in agreement with what have been seen for cracks induced by spherical indentation for similar materials, e.g. [23,24].

\section{Concluding remarks}

The development of cone cracks in brittle materials due to conical indentation is investigated. The finite element method is utilized along with a superposition technique valid for linear-elastic (brittle) materials. Based on the $J$-integral extracted from the finite element simulations, and (stress based) mode mixity in front of the crack tip, the stress intensity factor is established for each case considered. The starting location of the crack is assumed to be near or close to the tip of the indenter. By varying the material properties along with the crack length and crack direction, it is found that these types of cracks are prone to propagate in a $60^{\circ}$ angle relative the material surface. However, a "local maximum" of the stress intensity factor is found around $30^{\circ}$, in particular for materials with low $E / \sigma_{\mathrm{y}}$. Thus, under particular conditions, a crack may propagate in a $30^{\circ}$ direction. This could for example be triggered by pre-existing flaws favoring the $30^{\circ}$ direction.

An empirical functional form of the stress intensity factor is determined based on a second order exponential decay function. From this function a reverse algorithm is presented, which may be used to measure the fracture toughness of a material. Experimental data to verify the proposed method is unfortunately currently unavailable in the literature. However, we hope to conduct experimental investigations to confirm the technique at a later stage. 


\section{Acknowledgements}

The work of J.Y. and A.M.K. is supported by NSF DMR-0346664. The work of X.C. is supported by NSF CMS-0407743.

\section{References}

[1] Ogasawara N, Chiba N, Chen X. Representative strain of indentation analysis. J Mater Res 2005;20:2225-34.

[2] Ogasawara N, Chiba N, Chen X. Measuring the plastic properties of bulk materials by single indentation test. Scripta Mater 2006;54:65-70.

[3] Chen X, Yan J, Karlsson AM. On the determination of residual stress and mechanical properties by indentation. Mater Sci Eng: A 2006;416:139-49.

[4] Zhao M, Chen X, Yan J, Karlsson AM. Determination of uniaxial residual stress and mechanical properties by instrumented indentation. Acta Mater 2006;54:2823-32.

[5] Yan J, Karlsson AM, Chen X. Determining plastic properties of a bulk material with residual stress by using conical indentation. Int $\mathrm{J}$ Solids Struct, in press.

[6] Cook RF, Pharr GM. Direct observation and analysis of indentation cracking in glasses and ceramics. J Am Ceram Soc 1990;73:787-817.

[7] Lawn BR. Indentation of ceramics with spheres: a century of Hertz. J Am Ceram Soc 1998;81:1977-85.

[8] Zhang W, Subhash G. An elastic-plastic-cracking model for finite element analysis of indentation crack in brittle materials. Int J Solids Struct 2001;38:5893-913.

[9] Muchtar A, Lim LC, Lee KH. Finite element analysis of Vickers indentation crack processes in brittle solids using elements exhibiting cohesive post-failure behavior. J Mater Sci 2003;38:235-43.

[10] Chen X, Hutchinson JW, Evans AG. The mechanics of indentation induced lateral cracking. J Am Ceram Soc 2005;88:1233-8.

[11] Anstis GR, Chantikul P, Lawn BR, Marshall DB. A critical evaluation of indentation techniques for measuring fracture toughness: I, direct crack measurements. J Am Ceram Soc 1981;64:533-45.

[12] Lawn B, Evans A, Marshall D. Elastic-plastic indentation damage in ceramics - the median-radial crack system. J Am Ceram Soc 1980;63:574-81.

[13] Lawn BR, Fuller ER. Equilibrium penny-like cracks in indentation fracture. J Mater Sci 1975;10:2016-20.

[14] Lawn BR, Evans AG. A model for crack initiation in elastic/plastic indentation fields. J Mater Sci 1977;12:2195-201.

[15] Marshall DB. Controlled surface flaws in ceramics: a comparison of Knoop and Vickers indentation. J Am Ceram Soc 1983;66:127-33.

[16] Evans A, Charles E. Fracture toughness determinations by indentation. J Am Ceram Soc 1976;59:371-2.

[17] Niihara K. A fracture mechanics analysis of indentation-induced Palmqvist cracks in ceramics. J Mater Sci Lett 1983;2:221-3.

[18] Lankford J. Indentation microfracture in the Palmqvist crack regime: implications for fracture toughness evaluation by the indentation method. J Mater Sci Lett 1982;1:493-5.

[19] Lawn BR. Fracture of brittle solids. 2nd ed. Cambridge University Press; 1993.

[20] Chai H, Lawn BR. Hydraulically pumped cone fracture in brittle solids. Acta Mater 2005;53:4237-44.

[21] Evans AG, Fleck NA, Faulhaber S, Vermaak N, Maloney M, Darolia R. Scaling laws governing the erosion and impact resistance of thermal barrier coatings. Wear 2006;260:886-94.

[22] Chen X, Hutchinson JW, Evans AG. Simulation of the high temperature impression of thermal barrier coatings with columnar microstructure. Acta Mater 2004;52:565-71.

[23] Zeng K, Breder K, Rowcliffe DJ. The Hertzian stress-field and formation of cone cracks. 1. Theoretical approach. Acta Metall Mater 1992;40:2595-600.

[24] Zeng K, Breder K, Rowcliffe DJ. The Hertzian stress-field and formation of cone cracks. 2. Determination of fracture-toughness. Acta Metall Mater 1992;40:2601-5.

[25] Bush MB. Simulation of contact-induced fracture. Engng Anal Bound Elem 1999;23:59-66.

[26] Kocer C. An automated incremental finite element study of Hertzian cone crack growth. Finite Elem Anal Des 2003;39:639-60.

[27] Deriano S, Jarry A, Rouxel T, Sangleboeuf J, Hampshire S. The indentation fracture toughness (K-C) and its parameters: the case of silica-rich glasses. J Non-Cryst Solids 2004;344:44-50.

[28] Denry I, Holloway J. Elastic constants, Vickers hardness, and fracture toughness of fluorrichterite-based glass-ceramics. Dental Mater 2004;20:213-9.

[29] Bertoldi M, Sglavo VM. Soda-borosilicate glass: normal or anomalous behavior under Vickers indentation. J Non-Cryst Solids 2004;344:51-9.

[30] Shimizu S, Yanagimoto T, Sakai M. Pyramidal indentation load-depth curve of viscoelastic materials. J Mater Res 1999;14:4075-86.

[31] Bartsch M, Mircea I, Suffner J, Baufeld B. Interfacial fracture toughness measurement of thick ceramic coatings by indentation. Fractography Adv Ceram Ii 2005;290:183-90.

[32] Hutchinson JW. Mechanics of thin films and multilayers. Technical University of Denmark; 1996. 